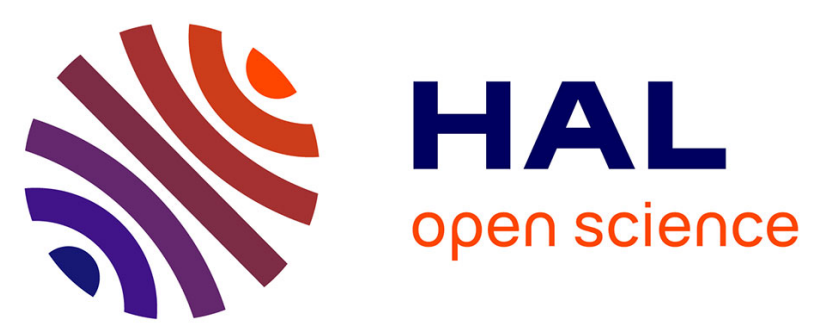

\title{
Mid-infrared Octave-spanning Supercontinuum Generation in an All-normal Dispersion SiGe Waveguide
} Milan Sinobad, Alberto Della Torre, Remi Armand, Barry Luther-Davies, Pan Ma, Stephen Madden, Arnan Mitchell, David J Moss, Jean-Michel Hartmann, Jean-Marc Fedeli, et al.

\section{To cite this version:}

Milan Sinobad, Alberto Della Torre, Remi Armand, Barry Luther-Davies, Pan Ma, et al.. Midinfrared Octave-spanning Supercontinuum Generation in an All-normal Dispersion SiGe Waveguide. CLEO: Science and Innovations, May 2021, San Jose, United States. pp.STh1L.4, 10.1364/CLEO_SI.2021.STh1L.4.hal-03406921

\section{HAL Id: hal-03406921 \\ https://hal.science/hal-03406921}

Submitted on 28 Oct 2021

HAL is a multi-disciplinary open access archive for the deposit and dissemination of scientific research documents, whether they are published or not. The documents may come from teaching and research institutions in France or abroad, or from public or private research centers.
L'archive ouverte pluridisciplinaire HAL, est destinée au dépôt et à la diffusion de documents scientifiques de niveau recherche, publiés ou non, émanant des établissements d'enseignement et de recherche français ou étrangers, des laboratoires publics ou privés. 


\title{
Mid-infrared Octave-spanning Supercontinuum Generation in an All-normal Dispersion SiGe Waveguide
}

\author{
Milan Sinobad, ${ }^{1}$ Alberto Della Torre, ${ }^{1}$ Remi Armand, ${ }^{1}$ Barry Luther-Davies, ${ }^{2}$ Pan $\mathrm{Ma},{ }^{2}$ Stephen Madden, ${ }^{2}$ \\ Arnan Mitchell, ${ }^{3}$ David J. Moss, ${ }^{4}$ Jean-Michel Hartmann, ${ }^{5}$ Jean-Marc Fedeli, ${ }^{5}$ Christelle Monat, ${ }^{1}$ and \\ Christian Grillet ${ }^{1}$ \\ 1 Université de Lyon, Ecole Centrale de Lyon, Institut des Nanotechnologies de Lyon (INL), 69131 Ecully, France \\ 2 Laser Physics Centre, Australian National University, Canberra, ACT 0100, Australia \\ 3 School of Engineering, RMIT University, Melbourne, VIC 3001, Australia \\ 4 Optical Sciences Centre, Swinburne University of Technology, Hawthorn, VIC 3122, Australia \\ 5 Université Grenoble Alpes and CEA, LETI, 17 Avenue des Martyrs 38054 Grenoble, France
}

\begin{abstract}
We report supercontinuum generation from an all-normal dispersion $\mathrm{SiGe-on- \textrm {Si }}$ waveguide pumped with 205 fs pulses at $4 \mu \mathrm{m}$. The supercontinua are spanning over an octave for both orthogonal polarizations of the fundamental mode. (C) 2020 The Author(s)
\end{abstract}

\section{Introduction}

Many gas molecules have strong vibrational absorption in the mid-infrared (mid-IR, $2.5-15 \mu \mathrm{m}$ ), allowing for air quality and environmental monitoring applications [1]. However, mid-IR technologies are still limited in their range of applications, primarily due to devices' size and prohibitive costs [2]. In this context, we aim to achieve a small footprint low-cost sensing platform with an integrated supercontinuum (SC) source to overcome these limits. Great efforts have been devoted to demonstrating octave-spanning SCs in mid-IR up to $8.5 \mu \mathrm{m}$ [3] and recently up to $13 \mu \mathrm{m} \mathrm{[4]} \mathrm{in} \mathrm{dispersion} \mathrm{engineered} \mathrm{SiGe-based} \mathrm{waveguides.} \mathrm{Furthermore,} \mathrm{we} \mathrm{performed} \mathrm{dispersion} \mathrm{trimming,}$ hence altering the SC properties, in a post-fabrication step [5], and we reported high coherence of an SC at frequencies separated by an octave [6]. Yet, SC in the all-normal dispersion (ANDi) regime, which offers the capability to maintain a single pulse with high coherence across the entire spectrum, has not been reported in a silicon-based chip in the mid-IR. Following the recent SC generation reports in the ANDi regime in various fiber platforms [7-9], a chalcogenide chip [10], we report here what we think to be the first octave-spanning mid-IR SC in an ANDi waveguide in a silicon-based chip [11].

\section{Octave-spanning $\mathrm{SC}$ in the ANDi regime}

We designed our SiGe ( $40 \%$ Ge in alloy) waveguides, with $5.0 \mu \mathrm{m} \times 2.7 \mu \mathrm{m}$ cross-section (see Fig. 1a), to operate in the ANDi regime with low group-velocity dispersion (GVD $<100 \mathrm{ps} / \mathrm{nm} / \mathrm{km}$ ) across an octave bandwidth between 3 and $6 \mu \mathrm{m}$ in both TE and TM polarizations (see Fig. 1b). GVDs reach their peak values of -4 and -15 $\mathrm{ps} / \mathrm{nm} / \mathrm{km}$, at 4.7 and $4.5 \mu \mathrm{m}$ wavelengths, for TE and TM polarizations, respectively.

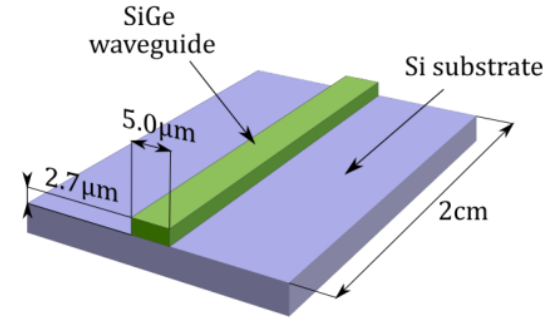

a) Waveguide schematics

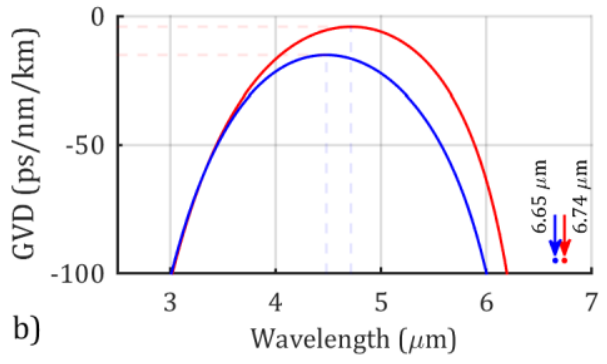

b)

Fig. 1. a) schematics of the $5.0 \mu \mathrm{m} \times 2.7 \mu \mathrm{m}$ cross-section air-clad SiGe-on-Si waveguide, b) calculated group velocity dispersion in TE (red), TM (blue) polarizations. Arrows show the corresponding cutoff wavelengths.

We characterized our waveguides using a standard free-space butt-coupling setup. We measured losses using a cutback method and a 7.5 pico-second laser, reaching loss as low as $0.3 \mathrm{~dB} / \mathrm{cm}$ between 4 and $5 \mu \mathrm{m}$ in TM polarization [11]. We then performed SC spectrum measurements by pumping a $2 \mathrm{~cm}$ long waveguide with $205 \mathrm{fs}, 63 \mathrm{MHz}$ repetition rate pulses at $4 \mu \mathrm{m}$. Fig. 2 shows the measured output spectra, spanning over an octave from 2.9 to $6.0 \mu \mathrm{m}$ and 2.8 to $5.7 \mu \mathrm{m}$, obtained by pumping the waveguide with $40 \mathrm{~mW}(5.7 \mathrm{~kW})$ coupled average (peak) power in TE and TM polarizations, respectively. 
Our simulations are in good agreement with the experimentally generated spectra (see black dash-dotted curve in Fig. 2). We calculated the degree of first-order coherence $g_{12}$ from 50 independent simulations showing a highdegree of coherence $\mathrm{g}_{12}$ equal to unity over the entire bandwidth (see red curve in Fig. 2).
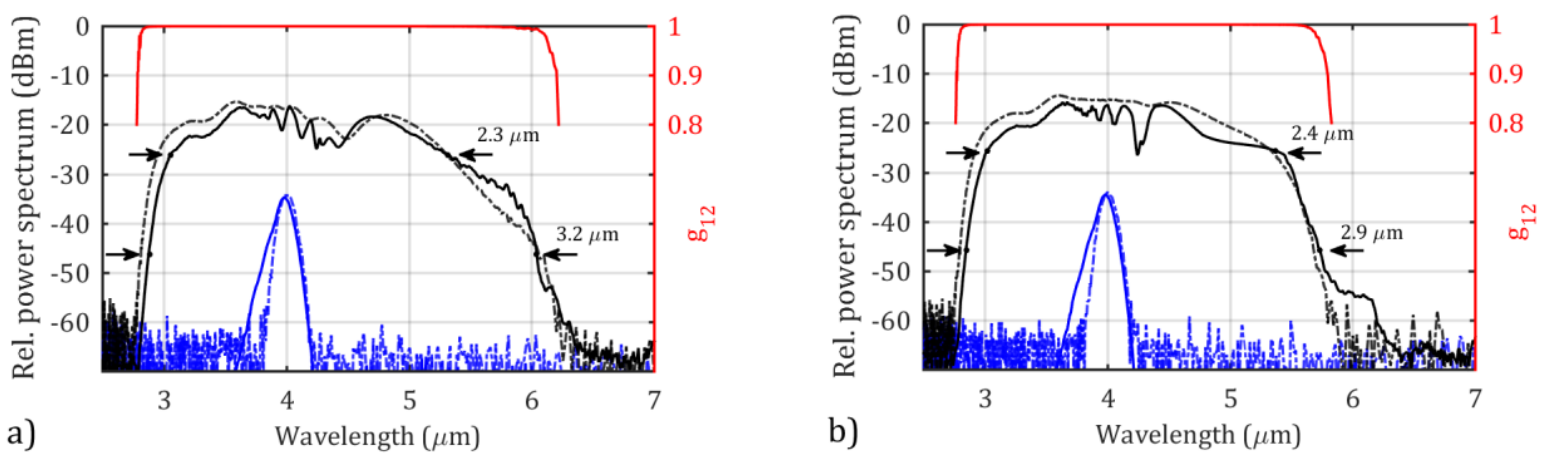

Fig. 2. Measured (solid) and simulated (dash-dotted), low-power (blue) and high-power SC (black) spectra in the a) $\mathrm{TE}$ and b) TM polarizations. The top red curve shows the calculated coherence of the SC spectrum. Black arrows show $-10 \mathrm{~dB}$ and $-30 \mathrm{~dB}$ spectral bandwidths.

A fully coherent SC from an ANDi waveguide, with a single pulse in time-domain, can be compressed to a fewcycle limit after compensating the second-and third-order dispersion [12]. Using simulations, we showed that it is possible, in principle, to exploit our SC to compress the $205 \mathrm{fs}$ pump pulses down to $22 \mathrm{fs}$ [11].

\section{Conclusion}

In conclusion, we have demonstrated fully coherent octave-spanning SCs in an ANDi SiGe-on-Si waveguide in both orthogonal polarizations of the fundamental mode. We found good agreement between measurements and simulations, allowing us to numerically confirm the full coherence of the generated SCs across their entire $(-30 \mathrm{~dB})$ bandwidths. The fully coherent supercontinua achieved in this regime are suitable for efficient on-chip pulse compression schemes.

\section{Funding}

H2020 European Research Council (ERC, GRAPHICS, 648546); Agence Nationale de la Recherche (ANR, MIRSiCOMB, ANR-17-CE24-0028).

\section{Acknowledgment}

We acknowledge the support of the International Associated Laboratory for Photonics between France and Australia (LIA ALPhFA).

\section{References}

[1] G. Z. Mashanovich, et al., "Germanium mid-infrared photonic devices," J. Lightw. Technol., 35, 624 (2017)

[2] D. Marris-Morini, et al., "Germanium-based integrated photonics from near- to mid-infrared applications," Nanophotonics, 7, 1781 (2018)

[3] M. Sinobad, et al., "Mid-infrared octave spanning supercontinuum generation to $8.5 \mu \mathrm{m}$ in silicon-germanium waveguides," Optica, 5, 360 (2018)

[4] M. Montesinos-Ballester, et al., "On-Chip Mid-Infrared Supercontinuum Generation from 3 to $13 \mu \mathrm{m}$ Wavelength," ACS Photonics, (2020)

[5] M. Sinobad, et al., "Dispersion trimming for mid-infrared supercontinuum generation in a hybrid chalcogenide/silicon-germanium waveguide," J. Opt. Soc. Am. B, 36, A98 (2019)

[6] M. Sinobad, et al., "High coherence at $\mathrm{f}$ and $2 \mathrm{f}$ of mid-infrared supercontinuum generation in silicon germanium waveguides," IEEE J. Sel. Top. Quantum Electron., 26, 8847400 (2020)

[7] N. Nishizawa and J. Takayanagi, "Octave spanning high-quality supercontinuum generation in all-fiber system," J. Opt. Soc. Am. B, 24, 1786 (2007)

[8] A. Al-Kadry, et al., "Broadband supercontinuum generation in all-normal dispersion chalcogenide microwires," Opt. Lett., 40, 4687 (2015)

[9] S. Xing, et al., "Linearly chirped mid-infrared supercontinuum in all-normal-dispersion chalcogenide photonic crystal fibers," Opt. Express, 26, 19627 (2018)

[10] Y. Yu, et al., "Experimental demonstration of linearly polarized 2-10 $\mu \mathrm{m}$ supercontinuum generation in a chalcogenide rib waveguide," Opt. Lett., 41, 958 (2016)

[11] M. Sinobad, et al., "Mid-infrared supercontinuum generation in silicon-germanium all-normal dispersion waveguides," Opt. Lett., 45, 5008 (2020)

[12] H. Tsuda, et al., "Second- and third-order dispersion compensator using a high-resolution arrayed-waveguide grating," IEEE Photonics Technol. Lett., 11, 569 (1999) 